\title{
Research of Catholyte Water on Experimental Graffi Tumor on Hamsters. Kangen Device for Catholyte Water
}

\author{
Ignat Ignatov \\ Scientific Research Center of Medical Biophysics (SRCMB), Bulgaria
}

\begin{abstract}
The paper describes the results of a pilot study aimed at the investigation of the influence of catholyte (electrolyzed alkaline water) on the development of tumors. In the experiments solid Graffi tumor was transplanted subcutaneously in the back of the experimental group of Golden Syrian hamsters. Tumor appearance and growth were registered every day. Blood parameters were measured on the $10^{\text {th }}$ and $25^{\text {th }}$ day after transplantation and blood smears were prepared. Hamsters treated with catholyte developed tumor with some delay compared to untreated (drinking tap water) ones. Also, the tumor growth was slow and the survival rate was increased. The analysis of blood parameters and cell morphology has shown significant differences in the value of some hematometric parameters and morphological changes of some blood cells. The obtained results suggest about the beneficial influence of catholyte and the possible use of it as a supporting non-invasive therapy of cancer diseases. The studies of the author show that the highest quality of Catholyte water if from device Kangen. The research of effect on Experimental Graffi Tumor on Hamsters is with co-authors Reneta Toshkova, Elissaveta Zvetkova and Georgi Gluhchev.
\end{abstract}

Keywords: Graffi tumor, catholyte, tumor growth, survival rate, mortality, blood parameters.

DOI: $10.7176 / \mathrm{JMPB} / 59-01$

Publication date:September $30^{\text {th }} 2019$

\section{Introduction}

Water is a natural and necessary medium for many biological molecules. Changes in its composition and structure can produce stimulating or inhibitory effects on the processes in the living things. Influenced by different factors water can change its acidity $\mathrm{pH}$, ORP (Oxidation Reduction Potential), and its physical structure. When electrochemical activation or electrolysis is applied the obtained catholyte receives high level of $\mathrm{pH}$ and negative ORP which leads to increased antioxidant effect. Due to this reason it could be expected that the catholyte would have protective and positive effect for oxidative stress-related diseases like diabetes and cancer.

Clinical examinations carried out by different scientists have demonstrated positive effect in case of diabetes type 2, telomere shortening in cancer cells and inhibition of their growth, suppression of side effects caused by the use of anticancer medications, favorable influence on the blood cells. Along with this it was proved that the activated water was not toxic for cells and tissues, and did not have mutagenic, cancerogenic, embryotoxic or immunotoxic effects.

For the evaluation of the influence of some medicine or therapy on tumor malignancies different parameters are used based on measurements of tumor development, survival rate, mortality, blood cells changes and others. In the last decade, the main hematometric indices (biomarkers) have been evaluated as diagnostic tools and prognostic parameters in patients with malignancies - cancer and leukemia.

Recent data from the scientific oncological literature evaluated that the NLR (neutrophil to lymphocyte ratio) is superior for predicting the long term survival of cancer patients . E.g., lower NLR $(\leq 2.0)$ is associated with good prognosis for breast cancer patients; a higher peripheral blood NLR ( $\geqq 5)$ was considered to indicate significantly and independently, a poor prognosis for breast cancer patients, gastric cancer patients, etc. Simultaneously, the total WBC count, absolute neutrophil- and lymphocyte counts alone, could be also statistically significant predictors of 5-year cancer patients' mortality.

At present, the data about the effects of electrolyzed alkaline water (catholyte) on tumor growth and hematological parameters in experimental tumor-bearing animals are absent.

The aim of this study is to examine the biological effects of catholyte on the tumor growth parameters, hematometric biomarkers (including main WBC count; absolute granulocyte; lymphocyte count; granulocyte; lymphocyte \% (percent), GLR (granulocyte to lymphocyte ratio), and blood cell morphology in hamsters with experimental Graffi myeloid tumor.

The authors have research of the project for influence with electromagnetic fields and infrared thermal fields on Graffi tumor $[15,16]$.

\section{Materials and Methods}

\subsection{Experimental animals}

In the trials hamsters, breed "Golden Syrian", aged 2-4 months, male and female, with weight around $100 \mathrm{~g}$, grown in individual plastic cages with free access to food and water were used 


\subsection{Experimental tumor}

The experimental Graffi solid tumor is maintained on a monthly basis in vivo in hamsters from the research team at IEMPAM-BAS (17) via subcutaneous (s.c.) transplantation of live tumor cells $\left(\left(1-2.10^{6}\right)\right.$ in the area of the back. Between days 7 and 15 in the spot of injection appear tumors, which grow progressively, and the hamsters die aproximately 30-35 days after the injection of tumor cells. In such a tumor model it is observed $100 \%$ attachment/appearance (transplantability) of umor and $100 \%$ mortality rate. Spontaneous regression, i.e. spontaneous shrinking and disappearance of the tumor is not observed.

\subsection{Catholyte water}

During the experiment catholyte water was produced every day using the Actvator-2 device, developed in the Institute of Information and Communication Technologies at the Bulgarian Academy of Sciences. In this way acidity $\mathrm{pH}$ of the water was kept between 9.0 and 9.5 .

\subsection{Experimental design.}

All the animals were divided into 4 groups each of 6 animals, as follows.

Gr. 1 The hamsters from this group started drinking catholyte water 10 days before the injection with $5 \times 10^{4}$ Graffi tumor cells per hamster in the back area, and continued drinking it until the end of the experiment.

Gr.2. This group was used as a control. The hamsters from it were s.c. injected with the same amount of tumor cells on the $10^{\text {th }}$ day of the experiment as the hamsters from Gr.1, and were receiving tap water all the time.

Gr.3 consisted of healthy hamsters drinking catholyte water during the experiment.

Gr.4 consisted of healthy hamsters drinking tap water all the time.

The first two groups have to reveal the influence of the catholyte water on the appearance and growth of transplanted tumor compared to the tap water, as well as for evaluation of haematological parameters and peripheral blood cell morphology.

The last two groups were used as control for hematological research.

\section{Measured parameters}

The following parameters of tumor development are determined:

- tumor transplantability success (\% of hamsters with tumor to the total number of injected ones),

- tumor size (the average diameter of tumor measured with caliper in $\mathrm{mm}$ ),

- survival and average survival (calculated for the respective group in days),

- lethality (\% of dead animals in the group).

Animals from each group were sacrificed preserving the ethical aspects of the European convention for protection of vertebrate animals, used for experimental and other scientific purposes (OJ L 222), and approved by the National Veterinary Medical Office in Bulgaria, and blood samples have been prepared at different time periods: on days 10 and 25 after Graffi tumor implantation. Hematological/hematometric parameters and indices as shown in Fig.1 were measured on the automated hematological analyzer BC-2800 Vet (Mindray, China).

The WBC/LR (White blood cells to Lymphocyte ratio and NLR (Neutrophil to lymphocyte ratio) were calculated.

\subsection{Statistical analysis}

For the evaluation of the significance of the differences between the average values of a specific parameter $t$-test was used at levels of significance $\alpha=0.10$ and $\alpha=0.05$, respectively.

\subsection{Research with spectral analyses with methods DNES and NES and chemical compositions of Catholyte water with different types of Catholyte water}

The device for DNES spectral analysis based on an optical principle was designed by A. Antonov. For this, a hermetic camera for evaporation of water drops under stable temperature $\left(+22-24{ }^{\circ} \mathrm{C}\right)$ conditions was used. The water drops were placed on a water-proof transparent pad, which consisted of thin maylar folio and a glass plate. The light was monochromatic with filter for yellow color with wavelength at $\lambda=580 \pm 7 \mathrm{~nm}$. The device measures the angle of evaporation of water drops from $72.3^{0}$ to $0^{0}$. The DNES-spectrum was measured in the range of $-0.08--0.1387 \mathrm{eV}$ or $\lambda=8.9-13.8 \mu \mathrm{m}$ using a specially designed computer program. The main estimation criterion in these studies was the average energy $\left(\Delta \mathrm{E}_{\mathrm{H} \ldots \mathrm{O}}\right)$ of hydrogen $\mathrm{O}$...H-bonds between $\mathrm{H}_{2} \mathrm{O}$ molecules in water samples with waters Catholyte,

\section{Results}

3.1. Parameters of tumor growth for Gr.1 and Gr.2.

Catholyte water was used as experimental therapy during two months. Animals have been examined every day until tumor detection and 2 times per week until 30 days after tumor transplantation. The tumor growth 
parameters have been registered regularly. The differences between the two groups are shown on (Figure.1).

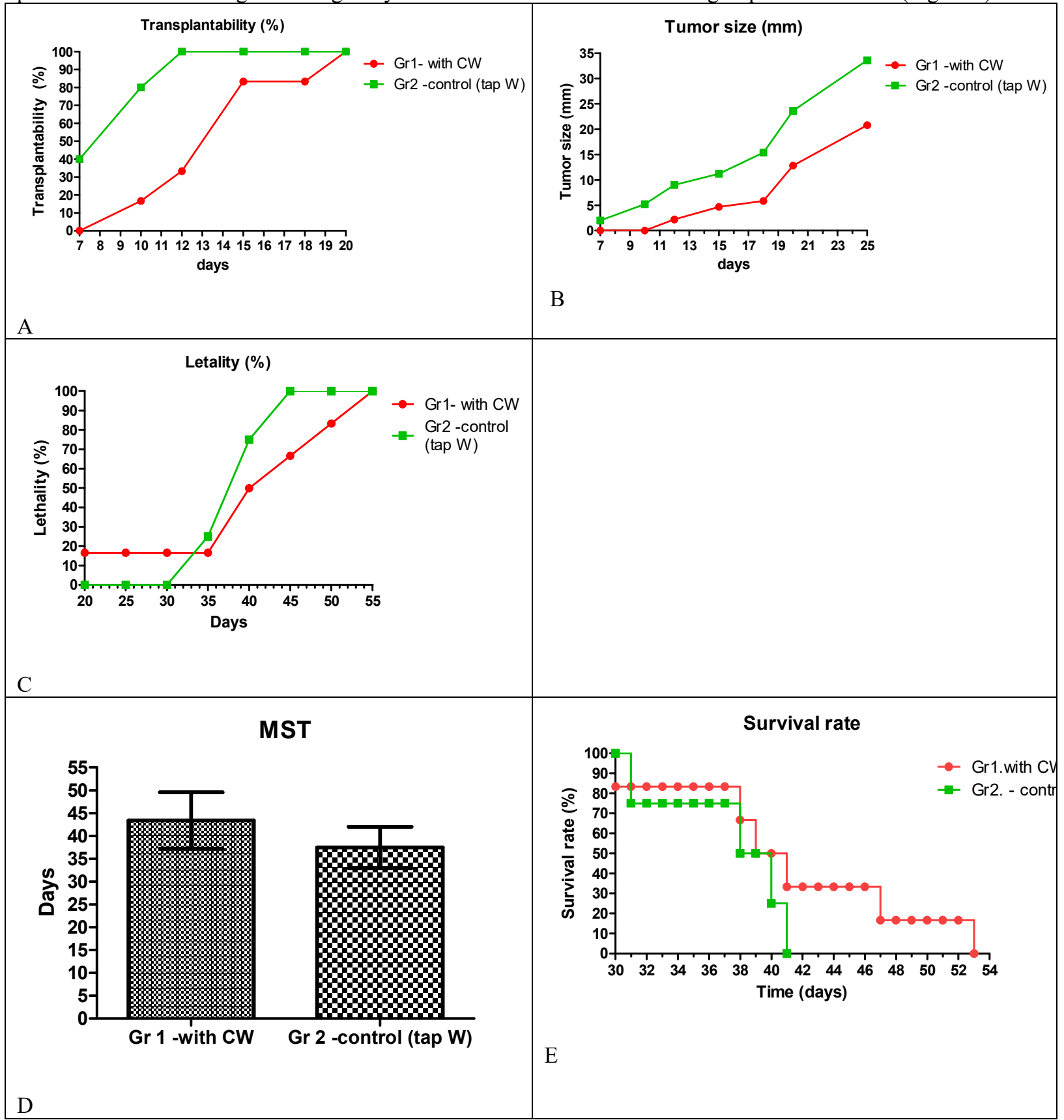

Figure 1. Biometric parameters of tumor growth for the hamsters from Gr.1 and Gr.2: A-transplantability in \%; B- tumor size in mm; C- lethality in \%; D- average survival time (AST) in days; E - Survival rate.

As can be seen from the graph on (Figure 1A) the tumor transplantation was delayed for the hamsters taking catholyte. While all the hamsters from Gr.2 developed tumor on the $12^{\text {th }}$ day this happened only for $1 / 3$ of hamsters from Gr.1. In the hamsters receiving catholite, tumors were detected at $100 \%$ on day 20 .

Similar effect is observed for the tumor size (Figure 1B). Until the $10^{\text {th }}$ day was not established subcutaneous firmness in none of the hamsters drinking catholyte. This group showed an inhibition in tumor growth rate as compared to control throughout the study period.

The increased lethality for the hamsters (Figure.1C) shows from Gr.2 after 35 days, compared with the hamsters from Gr.1. The control group (Gr.2) had a 100\% mortality on day 41, while in the group 1 - on the 53rd day of the study.

The evaluated average survival for Gr.1 is $43.4 \pm 6.9$ days, while it is $37.5 \pm 4.5$ days for Gr.2. Same conclusion could be taken from (Figure.1E).

These data suggest that the catholyte water slows down tumor development and as a result increases survival rate. 
The illustrations on (Figure.2) give visual impresion for the tumor development in Gr.1 and Gr.2.
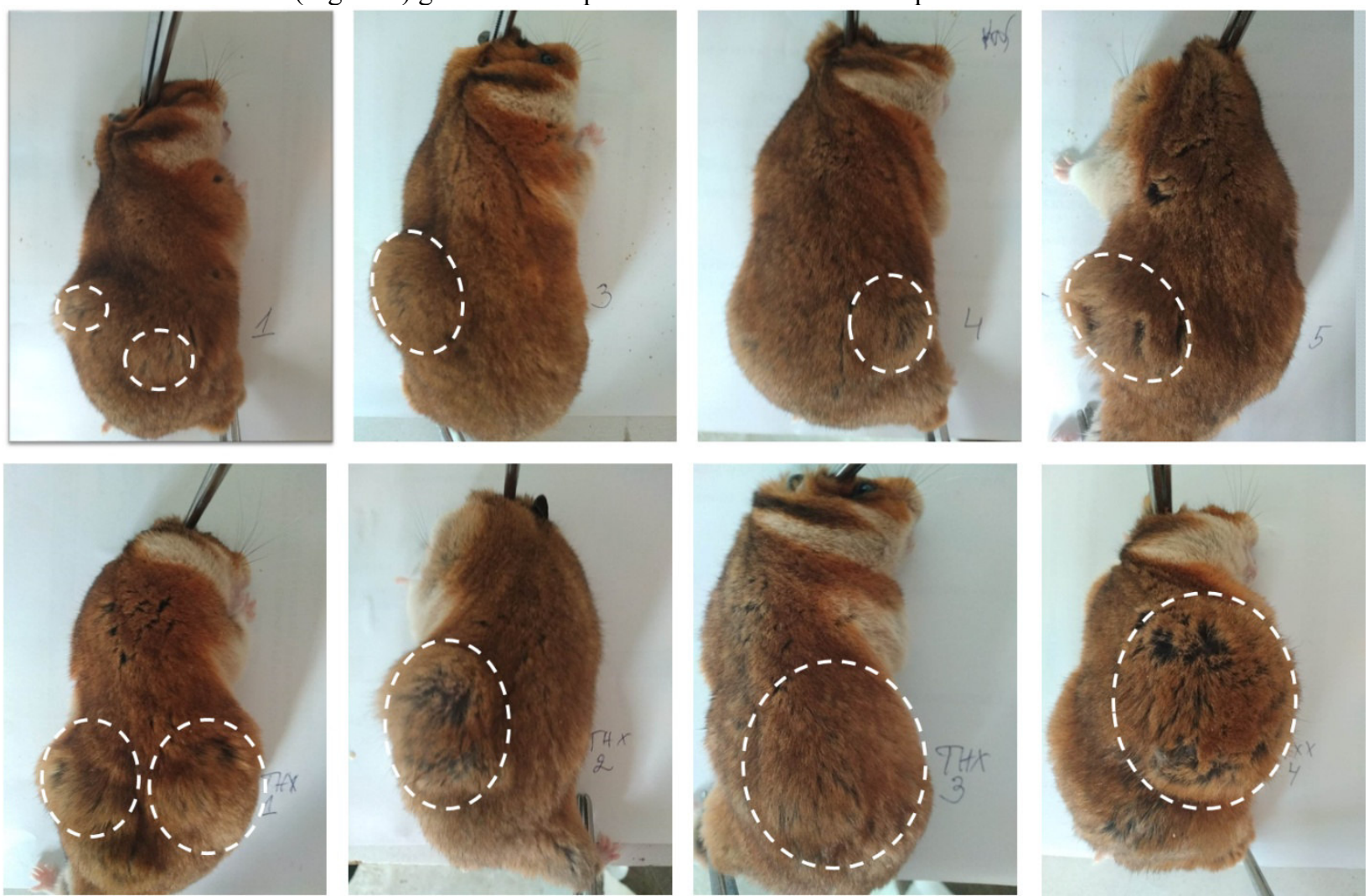

Figure 2. Images of hamsters from Gr.1 (upper line) and Gr.2 (bottom line) taken on the $25^{\text {th }}$ day after the tumor transplantation.

\subsection{Hematological parameters}

Hamsters from the trial and control groups were euthanised after the application of deep anaesthesia on the $10^{\text {th }}$ and $25^{\text {th }}$ day after tumor transplanting. The obtained blood was used to report hematological parameters, for serum and preparation of blood smears.

The evaluated parameters for all groups are displayed in (Table 1).

\begin{tabular}{|c|c|c|c|c|c|}
\hline \multicolumn{6}{|c|}{ Табл.1. Blood parameters on the $10^{\text {th/ }} \mathbf{2 5}^{\text {th }}$ day of study } \\
\hline Parameters & Units & \begin{tabular}{|l|} 
Tumor \\
(Catholyte)
\end{tabular} & \begin{tabular}{|l} 
Tumor \\
(Tap water)
\end{tabular} & \begin{tabular}{|l|} 
Healthy \\
(Catholyte)
\end{tabular} & \begin{tabular}{|l|} 
Healthy \\
(Tap water)
\end{tabular} \\
\hline WBC (Leukocytes) & X10\%/L & $3.8 / 47.9$ & $5.7 / 2.9$ & $6.8 / 5.8$ & $2.4 / 2.1$ \\
\hline Lymph & x10\% & $2.2 / 38.1$ & $0.7 / 0.5$ & $5.6 / 2.1$ & $1.4 / 1.2$ \\
\hline Mon & $\mathbf{X 1 0 ^ { 9 } / L}$ & $0.2 / 2.3$ & $0.5 / 0.2$ & $0.2 / 0.3$ & $0.1 / 0.1$ \\
\hline Gran & $\mathbf{X 1 0} / \mathbf{L}$ & $1.4 / 7.5$ & $4.5 / 2.2$ & $1.0 / 3.4$ & $0.9 / 0.8$ \\
\hline Lymph \% & $\%$ & $58.3 / 79.5$ & $12.8 / 16.5$ & 81.4/35.5 & $58.8 / 56.3$ \\
\hline Mon \% & $\%$ & $6.0 / 4.9$ & 8.5/7.3 & $3.3 / 5.2$ & $5.7 / 5.1$ \\
\hline Gran \% & $\%$ & $35.7 / 15.6$ & $78.7 / 76.2$ & $15.3 / 59.3$ & $35.5 / 38.6$ \\
\hline RBC (Erythrocytes) & $\times 10^{12} / L$ & $3.05 / 2.95$ & $4.77 / 5.58$ & $4.7 / 7.98$ & $4.25 / 5.36$ \\
\hline $\begin{array}{l}\text { HGB } \\
\text { (Haemoglobin) }\end{array}$ & g/ L & $67 / 83$ & $80 / 104$ & $85 / 137$ & $89 / 92$ \\
\hline HCT (Hematocrit) & $\mathbf{L} / \mathbf{L}$ & $0.165 / 0.204$ & $0.231 / 0.325$ & $0.267 / 0.445$ & $0.226 / 0.304$ \\
\hline $\begin{array}{l}\text { MCV (Mean red } \\
\text { blood cell volume) }\end{array}$ & fl & $54.2 / 69.2$ & $48.5 / 58.3$ & $57.0 / 55.8$ & $53.4 / 56.9$ \\
\hline $\begin{array}{l}\text { MCH (Average HGB } \\
\text { content in erythr) }\end{array}$ & pg & 21.9/28.1 & $16.7 / 18.6$ & $18.0 / 17.1$ & 20.9/17.1 \\
\hline $\begin{array}{l}\text { MCHC(mean conc } \\
\text { of } \mathrm{Hb}\end{array}$ & g/ L & $406 / 406$ & $346 / 320$ & $318 / 307$ & $393 / 302$ \\
\hline RDW & $\%$ & $12.6 / 22.9$ & $14.1 / 14.0$ & $15 / 11.7$ & $12.8 / 16.1$ \\
\hline PLT(Platelets) & X10\%/L & $132 / 491$ & $883 / 537$ & $250 / 488$ & $306 / 456$ \\
\hline $\begin{array}{l}\text { MPV(mean volume } \\
\text { of platelets) }\end{array}$ & f/L & $6.1 / 7.2$ & $4.9 / 5.6$ & $5.4 / 4.5$ & $5.1 / 5.7$ \\
\hline PDW & $\%$ & $19.8 / 19.8$ & $17.9 / 18.3$ & $18.9 / 17.0$ & $17.7 / 19.3$ \\
\hline PCT & $\%$ & $0.080 / 0.353$ & $0.432 / .300$ & $0.135 / 0.219$ & $0.156 / 0.259$ \\
\hline
\end{tabular}

Table 1. Blood parameters of $10^{\text {th }} / 25^{\text {th }}$ day of study 
The developing experimental Graffi myloid tumor in hamsters influenced diversely the two main WBC subpopulations - neutrophil granulocytes and lymphocytes (column 4). Significantly elevated WBC, granulocyte count and granulocyte number (\%) as well as significant reduction of absolute lymphocyte count and lymphocyte number (\%) were observed in the Graffi myeloid tumor-bearing hamsters (Gr.2, column 4) and (Figure 3). These effects are well expressed on the day 15-th, and are profound on the 25-th day in our experimental model. The treatment of tumor bearing animals with catholyte as drinking water improved the values of same parameters during the investigation (Gr.1, column 3) and (Figure 3).

The mean values and standard deviations of some parameters are shown in Table 2.

\begin{tabular}{|l|l|l|l|l|l|l|l|l|l|l|l|l|}
\hline Parameter & \multicolumn{2}{|l}{ Lymp\% } & \multicolumn{2}{l}{ Mon\% } & \multicolumn{2}{l|}{ Gran\% } & \multicolumn{2}{l|}{ RBC } & \multicolumn{2}{l|}{ MCHC } & PDW \\
\hline & $\mathrm{m}$ & $\mathrm{s}$ & $\mathrm{m}$ & $\mathrm{s}$ & $\mathrm{m}$ & $\mathrm{s}$ & $\mathrm{m}$ & $\mathrm{s}$ & $\mathrm{m}$ & $\mathrm{s}$ & $\mathrm{m}$ & $\mathrm{s}$ \\
\hline Gr.1 & 68.9 & 14.9 & 5.48 & 0.78 & 25.65 & 14.17 & 3 & 0.07 & 406 & 0 & 19.8 & 0 \\
\hline Gr.2 & 14.65 & 2.61 & 7.9 & 0.85 & 77.45 & 1.76 & 5.18 & 0.57 & 333 & 18.33 & 18.1 & 0.28 \\
\hline
\end{tabular}

Table 2. Mean values and standard deviations of blood parameters of Gr.1 and Gr.2

Table 3 contains the blood parameters for which significant difference between Gr.1 and Gr.2 was obtained at the corresponding confidence level.

\begin{tabular}{|r|c|c|c|c|c|c|}
\hline Parameter & Lymp $\%$ & Mon $\%$ & Gran $\%$ & RBC & MCHC & PDW \\
\hline$\alpha$ & 0.05 & 0.10 & 0.05 & 0.05 & 0.05 & 0.05 \\
\hline
\end{tabular}

Table 3. Significant difference between blood parameters of Gr.1 and Gr.2

Based on haematological values the WBCs/LR (White blood cells to Lymphocyte ratio) and NLR (Neutrophil to Lymphocyte ratio) hematometric indices were calculated. The both WBCs/LR and NLR indices are strongly elevated in tumor hamsters taking tap water and highly reduced in hamsters taking catholyte water. The values are similar to healthy hamsters (Figure 3).

Differences in some of the hematological parameters (WBCs, Ly) and WBCs/LR, and NLR hematometric index for groups are shown in (Figure 3).

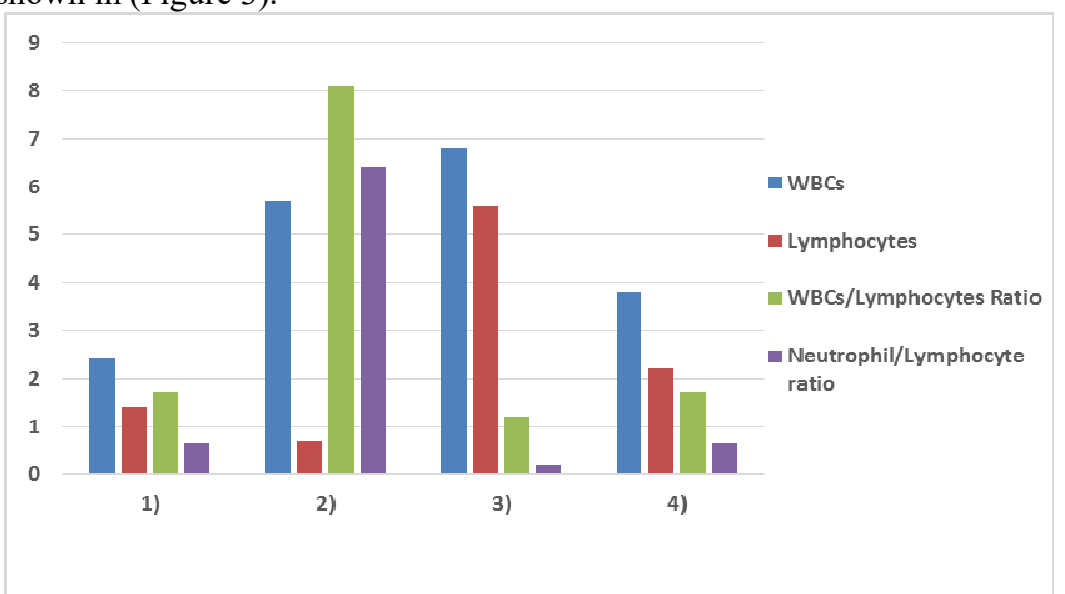

Figure3. WBCs (leukocytes) and Lymphocytes total count (x $\left.10^{9} / \mathrm{L}\right)$, and WBCs/Lymphocytes Ratio (at the $10^{\text {th }}$ day); 1) Controls; 2) -Untreated tumor-bearing hamsters; 3)-Healthy hamsters drinking catholyte; 4)-Tumorbearing hamsters drinking catholyte.

Significantly elevated WBC count and total granulocyte/neutrophil ratio were obtained in the untreated Graffi myeloid tumor-bearing hamsters (Gr.2).

Simultaneously, a significant reduction of the lymphocyte number was evaluated in the same animals.

Additionally, we obtained that catolyte water influenced (elevated) some main PLT-hematometric values in both - control and experimental animals (Table 1, PLT, MPV and and PDW). The hematometric results obtained were confirmed by our cytological studies on PLTs (thrombocytes) in the peripheral blood smears of hamsters where one could see clusters of activated thrombocytes - more pronounced in the blood of tumor-bearing animals (Fig.4 -i).

\subsection{Cytological study}

Images from blood smears are shown on (Figure. 4). 


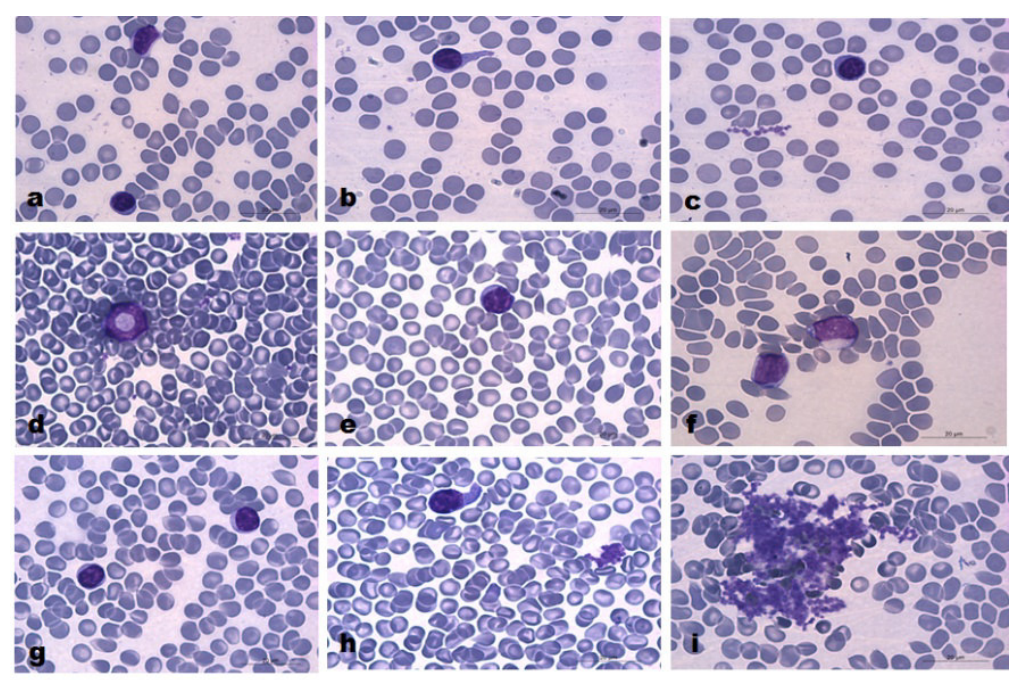

Figure 4. Images of blood smears as follows: upper line - healthy hamster treated with catholyte, middle line tumor-bearing hamster (control) drinking tap water, and bottom line -tumor- bearing hamster treated with catholyte. May Gruenwald Giemza staining. Objective X 100.

In the peripheral blood of healthy hamster, taking electrolyzed alkaline water (catholyte) activated lymphocytes with a large cytoplasmic pseudopode (ptotrusion), monocytes and platelets were observed (Figure 4 $-\mathrm{a}, \mathrm{b}, \mathrm{c})$ upper line.

Atypical myeloid cells and blast-like cells from the peripheral blood of Graffi myeloid tumor-bearing hamsters, at the day $10^{\text {th }}$ from tumor inoculation were observed. One could see atypical immature granulocyte with peripherally localized ring-shaped nucleus and eosinophile granules - in the central part of cytoplasm (Figure $4-\mathrm{d}, \mathrm{e}, \mathrm{f}$ ). middle line

In Graffi tumor bearing hamsters, treated with electrolyzed alkaline water (catholyte) atypical activated lymphocytes and cluster of PLTs in the peripheral blood smear were noticed. Lymphocytes from these hamsters, although atypical, show characteristic signs of activation as in healthy ones (Figure $4-\mathrm{g}, \mathrm{h}, \mathrm{i}$ ) bottom line.

\subsection{Electrolyzer for Catholyte water and Electrolyzer for Kangen Water \\ 3.4.1. Electrolyzer for Catholyte water}

The main stage of electrochemical treatment of water is the electrolysis of water or aqueous solutions with low mineralization as aqueous solutions of $0,5-1,0 \%$ sodium chloride $(\mathrm{NaCl})$, which occurs in the electrolysis cell, consisting of a cathode and an anode separated by a special semipermeable membrane (diaphragm) which separates water to alkaline fraction - the catholyte and acidic fraction - the anolyte (Figure 5). When the electric current is passing through the water, the flow of electrons from the cathode as well as the removal of electrons from the water at the anode is accompanied by series of redox reactions on the surface of the electrodes. As a result, new elements are being formed, the system of intermolecular interactions, as well as the composition of water and the water structure are changed.

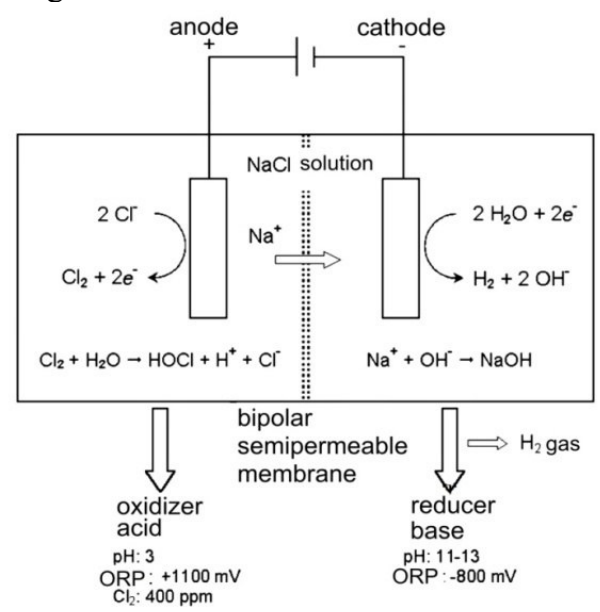

Figure 5. The diaphragm electrolysis method for the preparation of acid (anolyte) and alkali (catholyte) solutions via the electrochemical activation of sodium chloride 
The products of electrode reactions are the neutralized aqueous admixtures, gaseous hydrogen and oxygen generated during the electrolytic destruction of $\mathrm{H}_{2} \mathrm{O}$ molecules, metal cations $\left(\mathrm{Al}^{3+}, \mathrm{Fe}^{2+}, \mathrm{Fe}^{3+}\right)$ in the case of metal anodes made of aluminum and steel, and molecular chlorine. The gaseous hydrogen is generated at the cathode while the oxygen is produced at the anode. Water also contains a certain amount of hydronium ions $\left(\mathrm{H}_{3} \mathrm{O}^{+}\right)$depolarizing at the cathode with formation of the atomic hydrogen:

$$
\mathrm{H}_{3} \mathrm{O}^{+}+e^{-} \rightarrow \mathrm{H}+\mathrm{H}_{2} \mathrm{O} \text {, }
$$

In an alkaline environment a disruption of $\mathrm{H}_{2} \mathrm{O}$ molecules, accompanied by formation of atomic hydrogen and hydroxide ion $\left(\mathrm{OH}^{-}\right)$occurs:

$$
\mathrm{H}_{2} \mathrm{O}+e^{-} \rightarrow \mathrm{H}+\mathrm{OH}^{-}
$$

The reactive hydrogen atoms are adsorbed on the surface of the cathode, and molecular hydrogen $\mathrm{H}_{2}$, released in the gaseous form after recombination are formed:

$$
\mathrm{H}+\mathrm{H} \rightarrow \mathrm{H}_{2}
$$

At the same time atomic oxygen is released at the anode. In an acidic environment, this process is accompanied by the destruction of $\mathrm{H}_{2} \mathrm{O}$ molecules:

$$
2 \mathrm{H}_{2} \mathrm{O}-4 e^{-} \rightarrow \mathrm{O}_{2}+4 \mathrm{H}^{+},
$$

In an alkaline environment the $\mathrm{OH}^{-}$ions moving under the electrophoresis from the cathode to the anode are a source of oxygen:

$$
4 \mathrm{OH}^{-} \rightarrow \mathrm{O}_{2}+2 \mathrm{H}_{2} \mathrm{O}+4 e^{-}
$$

The normal redox potentials of these reactions compiles $+1,23 \mathrm{~V}$ and $+0,403 \mathrm{~V}$, respectively, but the process takes place in certain conditions of electric overload.

The cathodes are made of metals that require high electrical voltage (lead, cadmium) allowing for the generateion of reactive free radicals as $\mathrm{Cl}^{*}, \mathrm{O}^{*}, \mathrm{OH}^{*}, \mathrm{HO}_{2}^{*}$, which react chemically with other radicals and ions. In bulk oxidative processes products of electrolysis of water - oxygen $\left(\mathrm{O}_{2}\right)$, hydrogen peroxide $\left(\mathrm{H}_{2} \mathrm{O}\right)$ and hydrochlorine acid $(\mathrm{HClO})$ play a special role. During the electrolysis, an extremely reactive compound $\mathrm{H}_{2} \mathrm{O}_{2}$ is formed. Its formation occurs due to the hydroxyl radicals $\left(\mathrm{OH}^{*}\right)$ which are products of the discharge of hydroxyl ions $\left(\mathrm{OH}^{-}\right)$at the anode:

$$
2 \mathrm{OH}^{-} \rightarrow 2 \mathrm{OH}^{*} \rightarrow \mathrm{H}_{2} \mathrm{O}_{2}+2 e^{-}
$$

where $O H^{*}$ is the hydroxyl radical.

The chlorine-anion is transformed to $\mathrm{Cl}_{2}$ :

\subsubsection{Device for Kangen water}

$$
2 \mathrm{Cl}^{-} \rightarrow \mathrm{Cl}_{2}+2 e^{-}
$$

The device for Kangen water is applying with tap water. Kangen devices produce catholyte water with $\mathrm{pH} 8.5$; 9.0 and 9.5 with negative oxidation reduction potential (ORP) with values from (-500 to -250$) \mathrm{mV}$, The figure 6 shows one type of Kangen device.

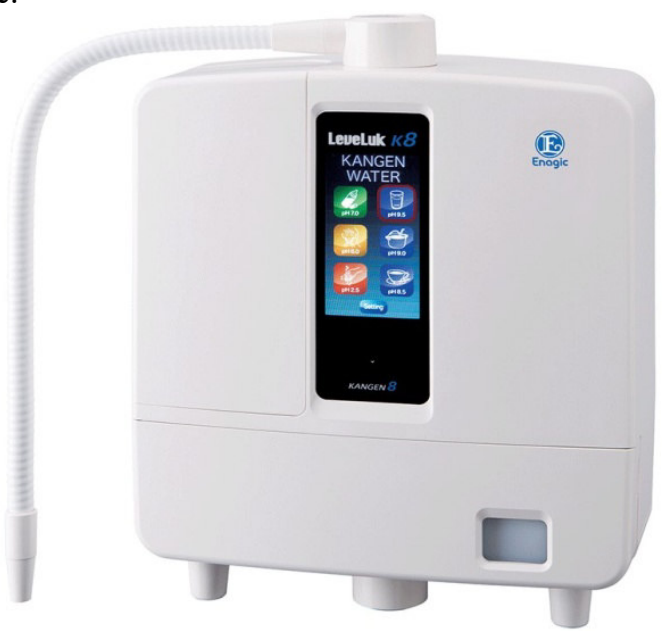

Figure 6. Kangen device

Kangen device has system for cleaning of tap water. The structure is on figure 7. 


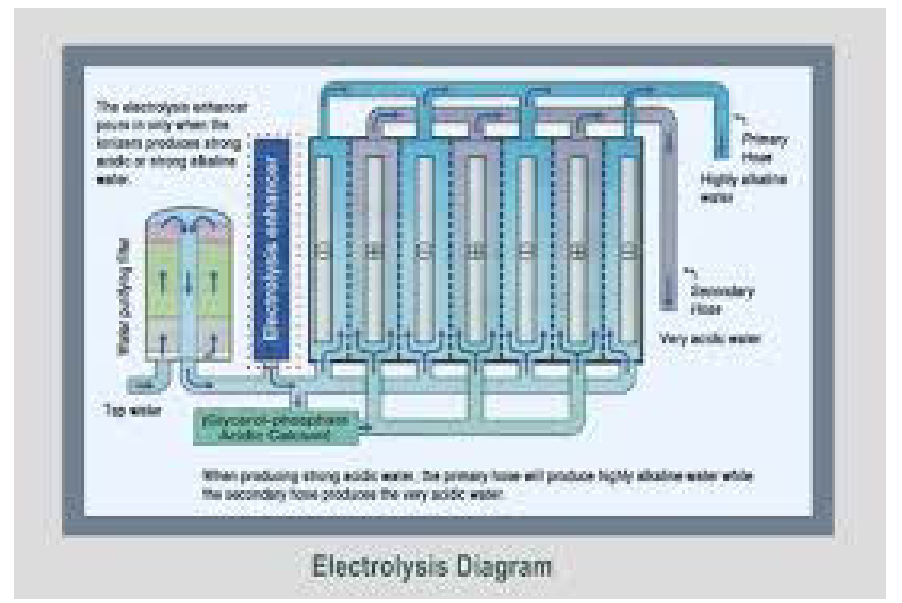

Figure 7. Kangen device with system for cleaning of tap water

Acknowledgement: The author expresses thankful for the support for the project with Catholyte water from Kangen device of Gergana Genova.

\section{Conclusion}

The influence of catholyte water on the development of Graffi tumor implanted in hamsters was assessed. Some delay in tumor growth and increased survival rate were observed. Significant differences in some of the blood parameters were noticed.

We obtained activated (small and medium-size) lymphocytes in the peripheral blood smears of healthy hamsters - treated with catholyte, instead of tap-water (Figure 4 - a,b,c). The same biological phenomenon was also evaluated partially in the peripheral blood of tumor-bearing animals, under the influence of catholyte (Figure 4-g,h). But in comparison to the activated immunocytes in healthy hamsters, the tumor-infiltration cells (TILs) in the tumor-bearing animals are soon atypical and insufficiently activated (or deactivated - in the preapoptotic or apoptotic states).

The appearance of the so-called blast-like cells (Figure $4-\mathrm{f}$ ) has been related to dissemination of the neoplastic disease and could be earlier obtained in the peripheral blood smears of untreated tumor-bearing animals. The results correlated also with changes in WBCs/LR and NLR hematometric indices obtained in the two experimental groups of treated and untreated tumor-bearing hamsters.

The elevated thrombocytes total count could be unfavorable predictor in cancer patients, having in view high risk of thrombogenesis and embolism. On the other hand, the catholyte water could be useful in cases with thrombocytopenia, but not in thrombocytoses, when application of electrolyzed water would be not recommended.

This study also further strengthens the role of WBC-hematometric indices in diagnosis and prognosis of cancer.

Catholyte water (investigated in vivo - in our experimental model of Graffi tumor-bearing hamsters), could improve TILs cellular immunity (immunomodulating, immunostimulating influence).

The first conclusion is that the developing experimental Graffi myeloid tumor in hamsters influenced diversely the two main WBC subpopulations (predominantly neutrophils) and lymphocytes. These diverse effects - well expressed on the $10^{\text {th }}$ day, are profound on the last (25th) day in our experimental model.

Our experimental results suggested that in the same model, the treatment of tumor-bearing animals with catholyte, as drinking water, improved the same hematometric indices to the normal values.

Thus, our second conclusion is that the catholyte water - employed instead of tap water in our experimental model with tumor-bearing hamsters, has a positive impact on the main hematometric indices e.g. WBCs/LR and NLR - neutrophil to lymphocyte ratio on $10^{\text {th }}$ day (Table 1) was: for WBCs/LR- 1.71 for a healthy hamster, 1.72 for a tumor-bearing, treated with catholyte and 8.14 for a tumor-bearing, untreated animal, and for NRL 0.64 for a healthy hamster, 0.64 for a tumor-bearing, treated with catholyte and 6.42 for a tumor-bearing, untreated animal, respectively.

All these points at a favorable influence of catholyte on the hematopoiesis both in case of tumor-bearing animals, and healthy ones.

The obtained results although promising are not definite. The two major shortcomings are as follows.

1) Small number of experimental animals. This could lead to deviation in the tendency of some parameters. Also, the increased number of observations could increase or decrease the obtained differences, thus changing the significance of the influence of catholyte on some of the blood parameters. 
2) Impossibility for drunken water control. This does not allow evaluating the proper relationship between the quantity of water and the observed differences.

Their overcoming will be the goal of our future work.

\section{References:}

Azab B et al. (2013) Pretreatment Neurophil/lymphocyte Ratio is Superior to Platelet/lymphocyte Ratio as a Predictor of Long-term Mortality in Breast Cancer Patients, Med. Oncol., 30::432

Dezayee, Z.M.I.\&Al-Nimer, M.S.M. (2016) The Clinical Importance of Measurement of Hematological Indices in the Breast Cancer Survival, World J Oncol; 7(1),1-4

Drossinakis Ch., Toshkova R., Zvetkova E, Ignatov, I. \& Gluhchev G. (2019) Methods of Research in Vivo Research of Therapeutical Effect in Hamsters with Experimental Myeloid Tumor of Graffi, 8th World Congress on Immunology, Pulsus, London, 3: 21.

Gluhchev G, Ignatov I, Karadzhov S, Miloshev G, Ivanov N\&Mosin O V. (2015) Electrochemically Activited Water: Biophysical and Biological Effects of Anolyte and Catholyte Types of Water, European Journal of Molecular Biotechnology, 7 (1); 12-26.

Hayashi H, Kawamura M. (2002) Clinical Improvements Obtained from the Intake of Reduced Water, Animal Cell Technology\&Applied Aspect, 12;31-36.

Hirahara N et al. (2016) Prognostic Values of Hematological Parameters in Patients with Esophageal Squamous Carcinoma, Int. J. Clin. Oncology, 21(5): 909-919.

Jia W. et al. (2015) Neutrophil-to-lymphocyte Ratio is Superior to the Lymphocyte -to-Monocyte Ratio for Predicting the Long Term Survival of Triple Negative Breast Cancer Patients, PlosOne; 10 (11).

Prilutsky V I \&Bakhir V M. Electrochemically Activated Water: Anomalous Properties, Mechanism of Biological Action, All Russian Scientific Research and Experimental Institude of Medical Engineering (VNIIIMT). 1997;1: 124. [in Russian].

Shirahata, S. (2000) Reduced Water for Prevention of Diseases, Animal Cell Technology: Basic \& Applied Aspects. 25-30.

Ignatov, I., Karadzhov, S., Gluhchev, G.\&Yakimov, I. (2018) Electromagnetically Activated Water - Properties and Effects, Bulgarian Journal of Public Health; 10 (4): 63-69.

Ignatov, I, Gluhchev, G. (2019) Effects of Electrochemically Activated Water Catholyte and Anolyte on Human Health, 8th World Congress on Immunology, Pulsus, London, 3: 12-13.

Ignatov, I. (2019) Research of Catholyte Water on Experimental Graffi Tumor on Hamsters. Kangen Device for Catholyte Water, Cancer Stem Cell, Epidemiology and Surgery, Seoul, pp. 25

Shirahata S, Hamasaki T, Teruya K. (2012) Advanced Research on the Health Benefit of Reduced Water, Trends in Food Science \& Technology,. 23:124-131

Ignatov I, Gluhchev, G, Karadzhov S., Miloshev G., Ivanov N, Mosin O V. (2015) Preparation of Electrochemically Activated Water Solutions (Catholyte/Anolyte) and Studying of their Physical-Chemical Properties, Journal of Medicine, Physiology and Biophysics,13: 18-38.

Qin Y-y et al. Red Blood Cell Distribution Width, Mean Platelet Volume and Cancer Antigen-125 as Inflammatory Markers in Differential Diagnosis of Ovarian Cancer. J Ovarian Res. 2018;11:10.

Toshkova, R., Ignatov, I., Zvetkova, E., Gluhchev, G. Drossinakis, Ch., (2019) Bioinfluence with Infrared Thermal and Electromagnetic Fields as a Therapeutic Approach of Hamsters with Experimental Graffi Myeloid Tumor, Journal of Natural Sciences Research, 9 (4):1-11.

Toshkova R. (1995) Attemps for Immunomodulation in Hamsters with Transplanted Myeloid Tumor, Previously Induced by Graffi Virus, Bulgarian Academy of Sciences, PhD Dissertation, Sofia.1995.

Toshkova, R., Tsvetkova, E., Ignatov, I., Gluhchev, G. Effects of Catholyte Water on the Development of Experimental Graffi Tumor on Hamsters, European Journal of Medicine, 2019. 7(1): 45-56.

Toshkova, R., Ignatov, I., Zvetkova, E., Gluhchev, G. (2019) Effects of Catholyte Water on the Development of Experimental Graffi Tumor on Hamsters, European Journal of Medicine, (1): 45-56.

Toshkova, R., Ignatov, I., Zvetkova, E., Gluhchev, G. (2019) Effects of Catholyte Water on the Development of Experimental Graffi Tumor on Hamsters, Cells\&Cellular Life Sciences Journal, 4 (1) 000140

Zvetkova E\&Fuchs D. (2017) Medical Significance of Simultaneous Application of Red Blood Cell Distribution Width (RDW) and Neopterin as Diagnostic Biomarkers in Clinical Practice, Pteridines; 28(3-4):133-140.

Zvetkova E. Quantitative Reduction in the RNP-Contents of Peripheral Blood Lymphocytes in Cancer Patients. Conference: $6^{\text {th }}$ Annual Meeting of the Federation-of-Clinical-Immunology-Societies Location: San Francisco, CA Date: JUN 07-11, Clinical Immunology, Volume: 2006, 119; Supplement S100. 